\title{
Dihydrochalcones and Chalcones of Some Flavanone Glycosides: Qualitative and Quantitative Determinations
}

\author{
Harald A. B. Linke and Douglas E. Eveleigh* \\ Department of Microbiology, New York University Dental Center, New York
}

(Z. Naturforsch. 30 b, 940-942 [1975]; received June 19, 1975)

Dihydrochalcones, Flavanone Glycosides, Sweeteners, Thin-layer Chromatography, Quantitative Analysis

\begin{abstract}
The chalcones and dihydrochalcones of the flavanone glycosides naringin, neohesperidin and hesperidin were separated and identified by thin-layer chromatography; a similar procedure was utilized to perform preparative TLC for purification of these compounds. A new spectrophotometric method for the quantitative determination of dihydrochalcones in the concentration range from 0.005 to $0.100 \%$ in aqueous or alcoholic solution is described as well as a detection method of these compounds in agar media for microbiological studies.
\end{abstract}

\section{Results and Discussion}

Since cyclamate was banned in 1969 from the U.S. market of artificial sweeteners, and saccharin was removed from the "generally-recognized-assafe" list of food additives by the Food and Drug Administration in 1972, the dihydrochalcone sweeteners derived from flavanone glycosides of citrus fruits have gained increased attention.

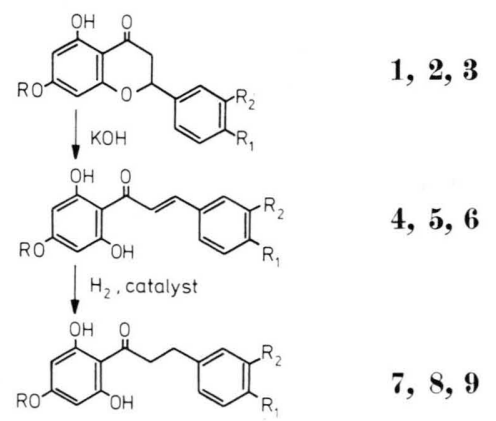

1: $\mathrm{R}=\beta$-neohesperidosyl, $\mathrm{R}_{1}=\mathrm{OH}, \mathrm{R}_{2}=\mathrm{H}$,

2: $\mathrm{R}=\beta$-neohesperidosyl, $\mathrm{R}_{1}=\mathrm{OCH}_{3}, \mathrm{R}_{2}=\mathrm{OH}$,

3: $\mathrm{R}=\beta$-rutinosyl, $\mathrm{R}_{1}=\mathrm{OCH}_{3}, \mathrm{R}_{2},=\mathrm{OH}$,

4: chalcone of 1 ,

5: chalcone of $\mathbf{2}$,

6: chalcone of $\mathbf{3}$,

7: dihydrochalcone of $\mathbf{1}$,

8: dihydrochalcone of $\mathbf{2}$,

$\mathbf{9}$ : dihydrochalcone of $\mathbf{3}$.

Requests for reprints should be sent to Dr. H. A. B. Linke, New York University Dental Center, Department of Microbiology, 421 First Avenue, New York, N.Y. 10010, USA.
The dihydrochalcones can be easily obtained chemically from the corresponding flavanone glycosides naringin (1), neohesperidin (2) and hesperidin (3) by alkaline hydrolysis and catalytic hydrogenation via the chalcones ${ }^{1-3}$. Naringin dihydrochalcone $(\mathbf{7})$ and neohesperidin dihydrochalcone (8) are intensely sweet tasting compounds, however, hesperidin dihydrochalcone $(9)^{* *}$ has no sweet taste 4 . In an attempt to produce these sweetening agents by microbial conversion of the flavanone glycosides ${ }^{5}$, some methods were explored for the quantitative determination of these compounds. The qualitative determination of some flavanone glycosides and their dihydrochalcones has already been reported ${ }^{6}$ as well as a quantitative method for the former compounds 7,8 ; we now describe a method for the quantitative determination of the latter compounds. The UV absorption peak in the range 407 to $409 \mathrm{~nm}$ of a complex with Neu's reagent $(\beta \text {-aminoethyl-diphenylborate })^{9}$ was used for their determination, since their natural UV maximum at $282 \mathrm{~nm}$ is interfered with by the UV absorption of the flavanone glycosides in this range. The complexes formed with the dihydrochalcones are stable for hours, whereas the complexes formed with the

* Department of Biochemistry and Microbiology, Cook College, Rutgers University, New Brunswick, N. J. 08903, USA.

** We thank Dr. R. M. Honowitz for a sample of hesperidin dihydrochalcone. 
flavanone glycosides and their chalcones are not; with time, the absorption at the maximum increases in case of the former and rapidly decreases in case of the latter. The UV maxima of the reagent complexes with 7, 8 and 9 are at $407 \mathrm{~nm}, 408 \mathrm{~nm}$ and $409 \mathrm{~nm}$, respectively; the absorption of the parent compounds in this range is negligible. The concentration of the dihydrochalcones can be determined by this method in aqueous or alcoholic solutions ranging from 0.005 to $0.100 \%$ (Fig. 1). An excess amount of Neu's reagent caused no interference in this method.

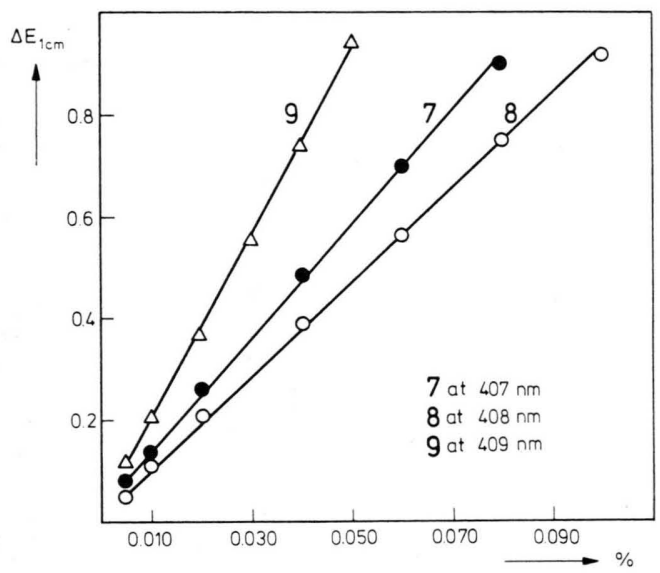

Fig. 1. Quantitative spectrophotometric determination of naringin dihydrochalcon (7), neohesperidin dihydrochalcone (8) and hesperidin dihydrochalcone $(\mathbf{9})$ in methanol $(0.2 \%$ Neu's reagent present).

Under strong alkaline conditions, e.g., the synthesis of naringin chalcone (4), neohesperidin chalcone $(5)$ and hesperidin chalcone $(6)^{3}$ several hydrolysis by-products of the flavanone glycosides are produced, which can only be removed from the desired product by column chromatography or preparative TLC. To monitor the purity of the synthesized products, thin-layer chromatography was utilized. A previously reported solvent system ${ }^{10}$ A (Table I) produced satisfactory results with silica gel thin-layer plates, although the presence of acetic acid in this system interfered with preparative TLC. For this reason the solvent system B (Table I) was developed, which produced excellent results in both TLC systems. The compounds 1 to 9 can be observed either under UV light $(375 \mathrm{~nm})$ or after developing with Neu's reagent (Table I). The $R_{f}$ values of both systems increase in the orders flavanone glycoside $<$ chalcone $<$ dihydrochalcone, $6<5<4$ and $9<8<7$ (Table I). Therefore, TLC in combination with Neu's reagent can also be utilized to distinguish between the chalcones and/or dihydrochalcones. The color reaction with Neu's reagent is also useful for the qualitative determination of flavanone glycosides, chalcones and dihydrochalcones in agar media for microbiological studies; the respective colors are beige-yellow, yellow-orange and brightyellow 5 .

\section{Experimental}

\section{Quantitative determination of the dihydrochalcones}

Standard solutions in final concentrations containing 0.005 to $0.100 \%$ of 7,8 and 9 and $0.200 \%$ of Neu's reagent in methanol were prepared. The absorption of each colored complex that formed was measured in aliquots of these solutions in $1.0 \mathrm{~cm}$ quartz cuvettes using a Cary 14 Recording

Table I. Chromatographic characteristics of some flavanone glycosides, their chalcones and dihydrochalcones.

\begin{tabular}{llcl}
\hline Compound & \multicolumn{2}{c}{$R_{j}$ value } & Color \\
& Solvent system A* & Solvent system B** & Neu's reagent \\
\hline Naringin (1) & 0.59 & 0.57 & Beige-yellow \\
Neohesperidin (2) & 0.56 & 0.55 & Beige-yellow \\
Hesperidin (3) & 0.52 & 0.54 & Beige-yellow \\
Naringin chalcone (4) & 0.64 & 0.65 & Yellow-orange \\
Neohesperidin chalcone (5) & 0.57 & 0.59 & Yellow-orange \\
Hesperidin chalcone (6) & 0.53 & 0.56 & Yellow-orange \\
Naringin dihydrochalcone $(\mathbf{7})$ & 0.65 & 0.67 & Bright-yellow \\
Neohesperidin dihydrochalcone $(\mathbf{8})$ & 0.58 & 0.63 & Bright-yellow \\
Hesperidin dihydrochalcone $(\mathbf{9})$ & 0.54 & 0.59 & Bright-yellow \\
\hline
\end{tabular}

* $n$-BuOH: $\mathrm{HAc}: \mathrm{H}_{2} \mathrm{O}=4: 1: 5$ (upper phase),

** $n$-BuOH saturated with $\mathrm{H}_{2} \mathrm{O}$. 
Spectrophotometer and read at the following wave lengths: $407 \mathrm{~nm}$ for $7,408 \mathrm{~nm}$ for 8 and $409 \mathrm{~nm}$ for 9. Standard curves are shown in Fig. 1.

\section{Thin-layer chromatography}

Silica gel plates (Merck, 60F-254, $0.25 \mathrm{~mm}$ ) were used for the separation of compounds $\mathbf{1}$ to $\mathbf{9}$, utilizing the solvent systems $\mathrm{A}$ ( $n$-butanol: glacial acetic acid: $\mathrm{H}_{2} \mathrm{O}=4: 1: 5$, upper phase) and $\mathrm{B}$ $\left(\mathrm{H}_{2} \mathrm{O}\right.$-saturated $n$-butanol). The produced spots were usually detected under UV light $(375 \mathrm{~nm})$ or after developing by spraying the plates with $1 \%$ Neu's reagent in methanol. The $R_{f}$ values $(6 \mathrm{~h}$ running time at $23^{\circ} \mathrm{C}$ ) and colors are summarized in Table I. For preparative TLC silica gel plates (Merck, 60 F-254, $2 \mathrm{~mm}$ ) were utilized in combination with solvent system $\mathrm{B}$.

1 R. M. Horowitz and B. Gentili, U. S. Patent 3,087,821 (April 30, 1963).

2 L. Krbechek, G. Inglett, M. Holik, B. Dowling, R. Wagner, and R. Riter, J. Agr. Food Chem. 16, 108 [1968].

3 H. A. B. Linke and D. E. Eveleigh, Z. Naturforsch. $30 \mathrm{~b}, 606$ [1975].

4 R. M. Horowitz and B. Gentill, J. Agr. Food Chem. 17, 696 [1969].

5 H. A. B. Linke, S. Natarajan, and D. E. EveLeigh, Abstr. Ann. Meet. Amer. Soc. Microbiol. 1973, 171, P 184.
Detection of flavanone glycosides, chalcones and dihydrochalcones in agar media for microbiological studies 5

The surface of the agar plates was flooded with $1 \mathrm{ml}$ of Neu's reagent (1\% in methanol). After 5 minutes the colors of the complexes that formed, were evaluated in day light; flavanone glycosides, when present in the agar medium, produced a beige-yellow, chalcones a yellow-orange and dihydrochalcones a bright-yellow color.

This work was supported in part by National Science Foundation (grant number GI $34287 \mathrm{C}$ ). Paper of the Journal Series, New Jersey Agricultural Experiment Station, Rutgers University - The State University of New Jersey, New Brunswick, N.J. 08903.

${ }^{6}$ B. Gentill and R. M. Honowitz, J. Chromatogr. 63, 467 [1971].

7 R. Goren and S. P. Monselise, J. of the A. O. A. C. 47, 677 [1964].

8 A. Ciegler, L. A. Lindenfelser, and G. E. N. Nelson, Appl. Microbiol. 22, 974 [1971].

9 R. Neu, Naturwissenschaften 44, 181 [1957].

10 T. B. Gage, C. D. Douglass, and S. H. Wender, Analyt. Chem. 23, 1582 [1951]. 